\title{
Docetaxel: Solid state characterization by X-ray powder diffraction and thermogravimetry
}

\author{
L. Zaske, M.-A. Perrin et F. Leveiller
}

AVENTIS PHARMA, Global Pharmaceutical Development, Pharmaceutical Sciences, Material and Drug Delivery Design, CRV1, 13 quai Jules Guesde, BP. 14, 94403 Vitry-sur-Seine cedex, France

\begin{abstract}
Docetaxel, a stoichiometric hydrate containing three water molecules per molecule of drug substance, is thermodynamically stable under ambient conditions of pressure, temperature and relative humidity. Dehydration of this form was subjected to X-ray powder diffraction (XRPD) and thermogravimetric experiments. To obtain a better understanding of the observed structural changes between trihydrate and dehydrated forms, the crystalline structure of docetaxel was refined using high resolution XRPD data coupled with an $a b$ initio direct space method.
\end{abstract}

\section{INTRODUCTION}

Docetaxel (see Figure 1), which molecular formula is $\mathrm{C}_{43} \mathrm{H}_{53} \mathrm{NO}_{14.3} 3 \mathrm{H}_{2} \mathrm{O}$, corresponds to the trihydrate form of Taxotere ${ }^{\circledR}$ ( $N$-tert-butoxycarbonyl-10-deacetyl- $N$-debenzoyltaxol). Taxotere ${ }^{\circledR}$, an intermediate in the hemi-synthesis of taxol [1], is obtained from yew needles. It is an antineoplastic agent, which pharmacological properties are superior to those of taxol ${ }^{\mathbb{B}}$.

Docetaxel is thermodynamically stable under ambient conditions of pressure, temperature and relative humidity. Under a nitrogen stream, i.e. in a dynamic dry atmosphere $(0 \% \mathrm{RH})$, or under heat, docetaxel is dehydrated and forms an anhydrous crystal phase. The dehydration was monitored and characterised using X-ray powder diffraction (XRPD) under a nitrogen gas stream and heat, and using also thermogravimetry under a nitrogen gas stream (TGA/DSC) and under variable partial water vapour pressure (water sorption-desorption isotherms).

To gain a better understanding of this transformation at the molecular level, the crystal structure of docetaxel was solved. As a conventional structure determination from single crystal data could not be obtained because of unsuitable crystal morphology (extremely thin plates despite several attempts to generate thick crystals, see Figure 2), high resolution XRPD, coupled with a direct space method [2] was carried out. Until now, only the crystal structure of a mixed Taxoter ${ }^{\circledR}$ solvate (Taxotere/methanol/water : $1 / 1 / 1$ ) has been published [3].

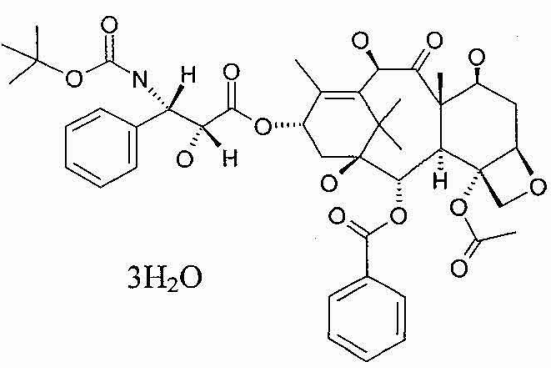

Figure 1. Molecular structure of docetaxel $(\mathrm{MW}=862)-14$ torsion angles

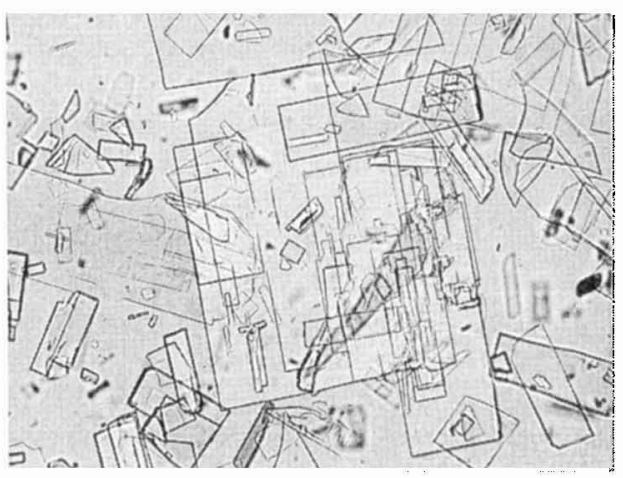

Figure 2. Crystalline morphology of docetaxel (optical microscopy with $\mathrm{M}=100 \mathrm{X}$ ) 


\section{EXPERIMENTAL}

\subsection{Preparation of docetaxel}

Docetaxel is very slightly soluble in water $(3 \mu \mathrm{g} / \mathrm{mL})$, but is soluble in ethanol $(160$ $\mathrm{mg} / \mathrm{mL})$ or acetone $(180 \mathrm{mg} / \mathrm{mL})$. The docetaxel crystals studied here were obtained by adding water to a solution of Taxotere ${ }^{\circledR}$ in ethanol.

\subsection{High resolution XRPD (European Synchrotron Radiation Facility : ESRF)}

High resolution XRPD data were recorded on beam line BM16. To limit preferential orientation effects of crystallites, a Debye-Scherrer geometry was used coupled with a rotating capillary filled with ground docetaxel powder.

\subsection{Conventional XRPD under nitrogen stream and heat}

The analyses were carried out using a Siemens-Bruker D5000 diffractometer equipped with an Anton-Paar TTK temperature chamber. The camera used Bragg-Brentano $(\theta-\theta)$ focusing geometry in the reflection mode. A cobalt anode tube with an iron filter provided incident radiation. The temperature was ramped at $0.05 \mathrm{~K} / \mathrm{s}$.

\subsection{Thermogravimetric analyses and water sorption-desorption isotherms}

The weight mass loss depending on temperature (TGA) was measured on a TA Instruments (TAI) TGA-HR 2950 thermal analyser. Differential scanning calorimetry (DSC) was carried out on a (TAI) DSC2010 thermal analyser. The water activity isotherms $(\mathrm{T}=298 \mathrm{~K}$ ) were measured on a Dynamic Vapour Sorption (DVS) analyser under nitrogen gas stream.

\section{RESULTS AND DISCUSSION}

\subsection{Crystal structure of docetaxel}

Indexing carried out with DICVOL91 [4] provided a solution with very high figures of merit, indicating the high precision of the synchrotron XRPD data $(157$ and $1219[0.0006,27]$ for $\mathrm{M}_{20}$ and $\mathrm{F}_{20}$ respectively). The solution was then refined using NBS*AIDS83 [5]. The crystal system is orthorhombic (space group $P 2{ }_{1} 2_{1} 2_{1}$ ). The unit cell parameters (at room temperature) are : $\quad a=39.9345(16) \AA, \quad b=12.7749(4) \AA, \quad c=8.6644(5) \AA \quad$ with $\mathrm{V}=4420.2(2) \AA^{3}$. The number of motifs (Z) per cell is 4 and the density of the crystal is 1.295 .

Based on the molecular geometry obtained from the structure of the mixed solvate [3], the structure was solved (29 degrees of freedom) using an $a b$ initio direct space approach. The method is based on a simulated annealing algorithm (PowderSolve [6]). Rietveld refinement (Powder Refinement in the Materials Studio ${ }^{\mathbb{1}}$ application) completed the solution. The final structure was obtained with an $R_{w p}$ profile factor of $9.3 \%$.

Figure 3 shows the close agreement between the experimental XRPD pattern and the simulated pattern of the solution. The absence of overlaps between molecules and the presence of appropriate hydrogen bonds in the physical model generated in this manner support the physical reality of the mathematical solution. 


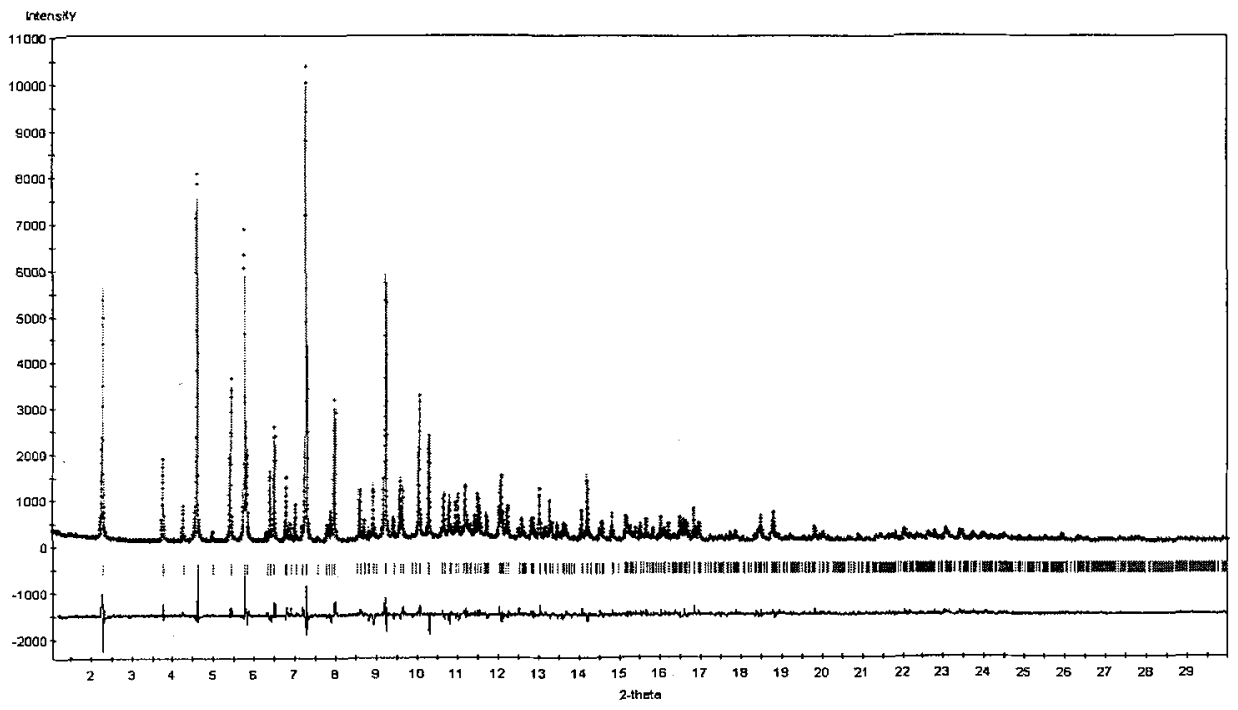

Figure 3. Rietvelt plot of docetaxel

The analysis of docetaxel crystal packing (see Figure 4) clearly shows a structure of bilayers separated by water molecules, similar to that found in surfactant systems. The amphiphilic character of Taxotere ${ }^{\circledR}$ molecules favours such a structure. The hydrophobic parts (tert-butyl and methyl groups, aromatic rings) interact strongly within the core of the bi-layer, leaving the hydrophilic parts (hydroxyl and carboxyl groups) pointed outward.

The internal stability of the bi-layer is reinforced by a strong hydrogen bond in the plane of the bi-layer, between the amide hydrogen of each Taxotere ${ }^{\circledR}$ molecule and the oxetane oxygen of the adjacent molecule.

The cohesion between bi-layers is provided by a strong hydrogen bond between two Taxotere ${ }^{(\mathbb{B}}$ molecules in the opposing bi-layers, and also by the three water molecules (each Taxotere ${ }^{\circledR}$ molecule forms five hydrogen bonds with the three water molecules, the latter interacting among themselves via hydrogen bonding).

This bi-layer organisation is similar to that observed within the mixed solvate structure [3]. The bi-layers of both structures are totally superimposable. Only their relative packings change depending on the different types of solvent molecules present (water and/or methanol).

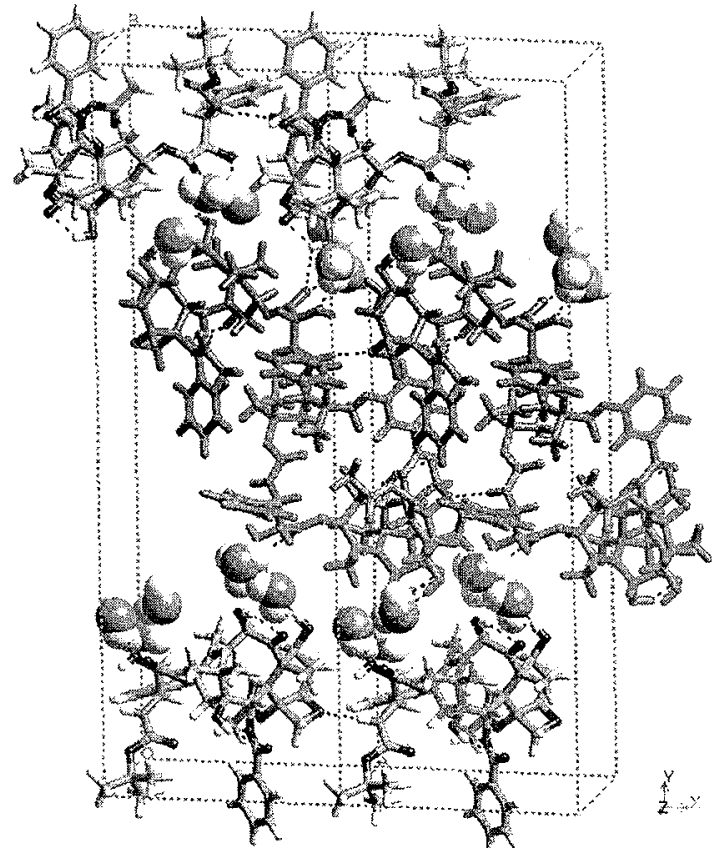

Figure 4. Crystalline structure of docetaxel 
Calculation of the crystal morphology in vacuum by the "Attachment Energy" method (see Figure 5) yields a platelet shape in the bi-layer plane, which is completely consistent with the experimental habit (see Figure 2). The difficulty of obtaining more isotropic crystal morphologies arises from the strong cohesion within the bi-layer, which is essentially hydrophobic, and the presence of a polar solvent medium (ethanol/water), which favours the hydrophobic crystal growth.

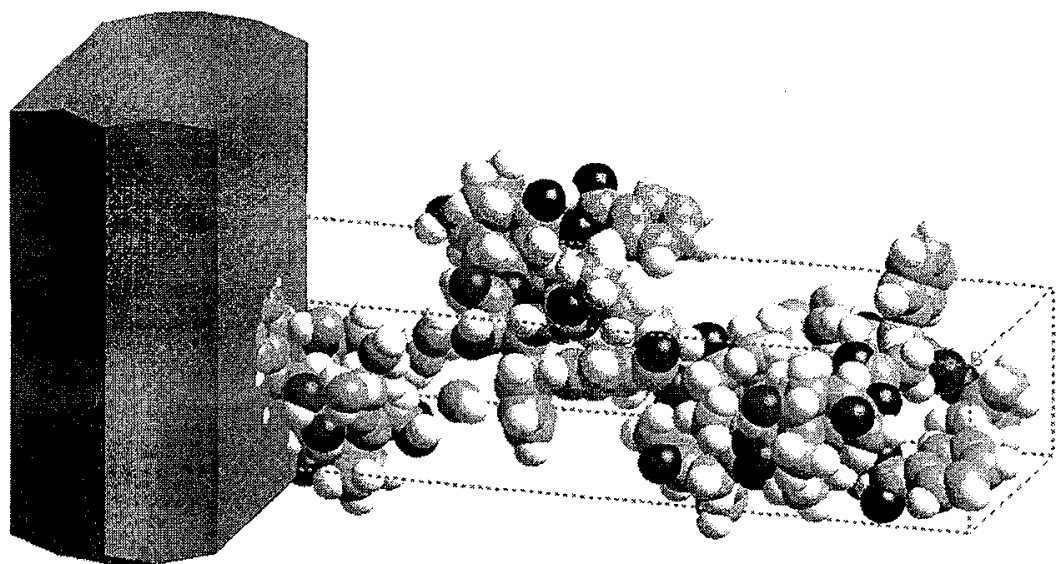

Figure 5. Calculated crystalline morphology of docetaxel

\subsection{Dehydration study of docetaxel}

Comparison of the DSC and TGA diagrams (see Figure 6) clearly shows dehydration of docetaxel prior to melting. Over the temperature range in which an endothermic event was observed by DSC, the measured weight loss was $5.9 \% \mathrm{w} / \mathrm{w}$ (theoretical water content in docetaxel is $6.3 \% \mathrm{w} / \mathrm{w})$. The DSC diagram shows a second endotherm, which corresponds to the melting point $\left(T_{\text {onset }}=434 \mathrm{~K}\right.$ ) preceding the beginning of thermal decomposition

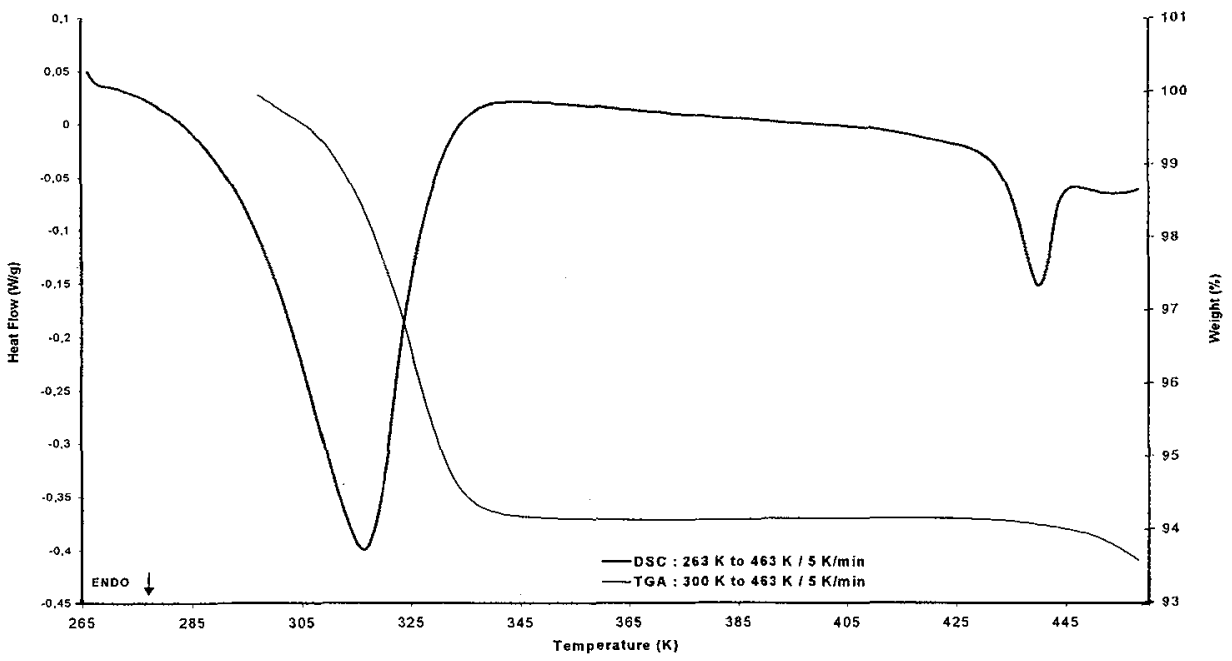

Figure 6. DSC and TGA diagrams of docetaxel 
During a thermal cycle (heating- 1 to $373 \mathrm{~K}$, cooling to room temperature, followed by a second heating-2 to melting, see Figure 7) the endotherm attributed to the loss of water present during the first heating mostly disappeared in the second heating. Only the endotherm related to melting of the anhydrous phase was observed.

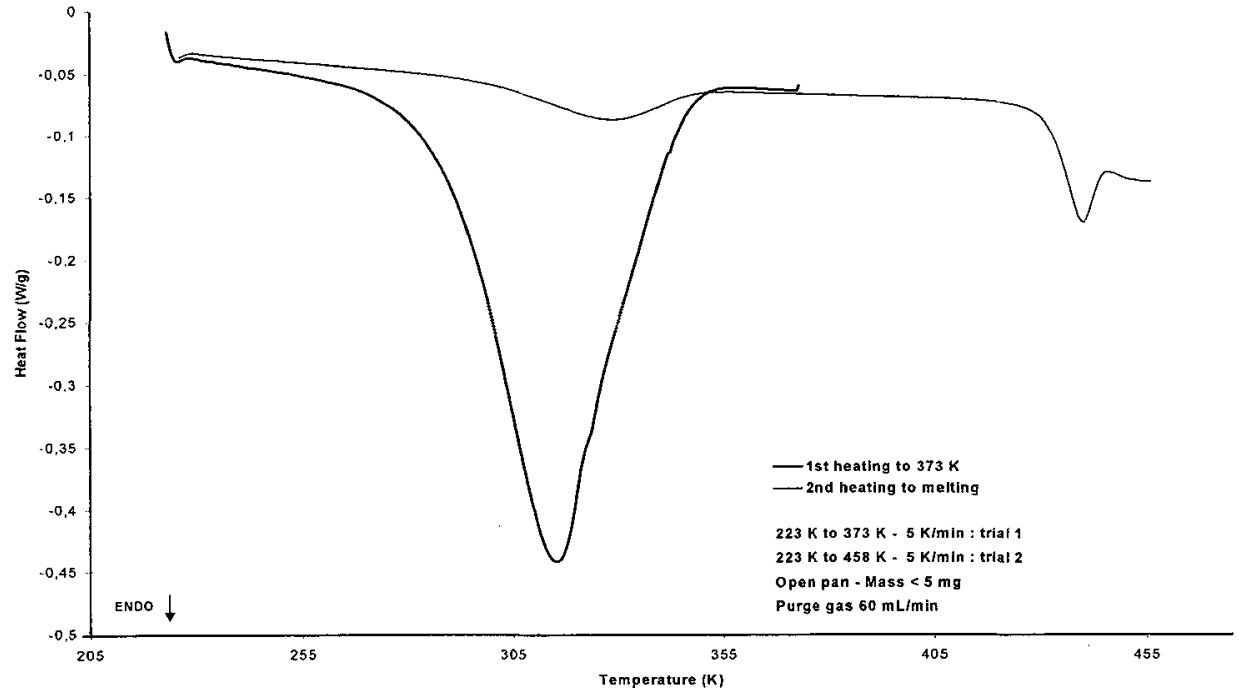

Figure 7. DSC diagrams of docetaxel (thermal cycle)

The water sorption-desorption isotherms at $298 \mathrm{~K}$ are given in Figure 8 . Above $20 \% \mathrm{RH}$, the continuous water uptake slowed down considerably until it reached a maximum at $5.1 \%$ $\mathrm{w} / \mathrm{w}$. The deviation from the theoretical value $(6.3 \% \mathrm{w} / \mathrm{w})$ for the trihydrate reached $1.2 \%$ $\mathrm{w} / \mathrm{w}$, i.e. 0.5 mole of water. This observation suggests the existence of a hemi-hydrate form which was not completely dehydrated by keeping at $298 \mathrm{~K}$ for 24 hours under a dry nitrogen gas stream $(0 \% \mathrm{RH})$.

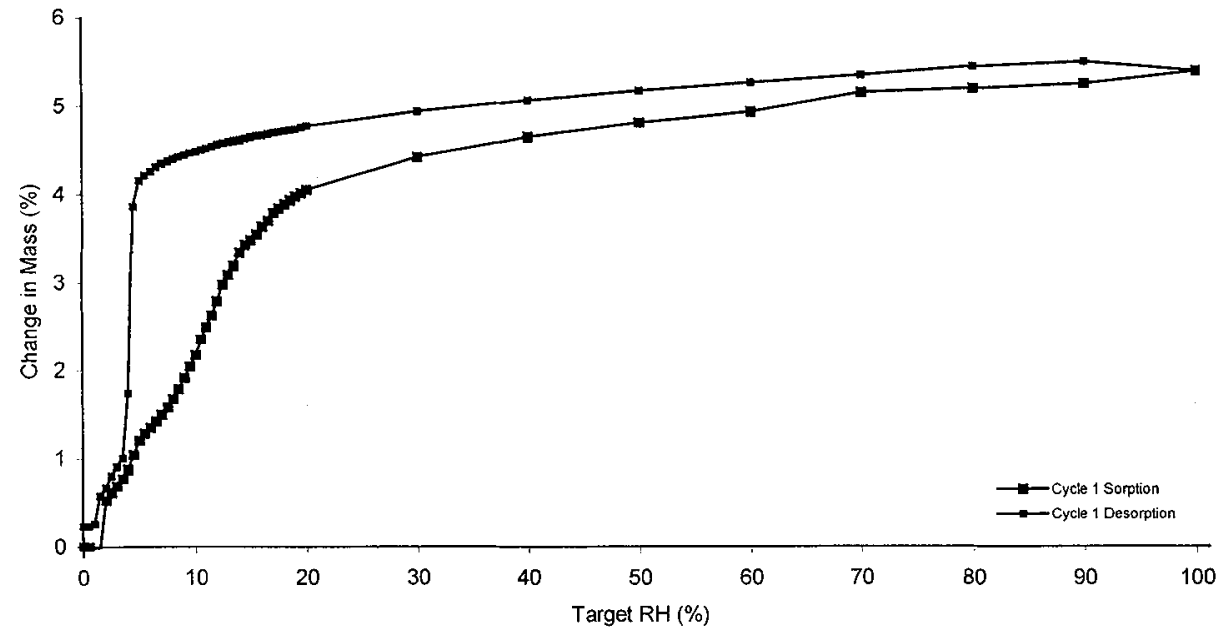

Figure 8. Water sorption-desorption isotherms of docetaxel (298 K) 
The structural changes following the loss of water molecules were monitored by XRPD under heat (see Figure 9). The trihydrate form was placed in a nitrogen gas stream, heated to $373 \mathrm{~K}$ and maintained at an isotherm for 15 hours (HPLC showed no chemical degradation). The first structural changes occurred within a few minutes and continued for several hours.

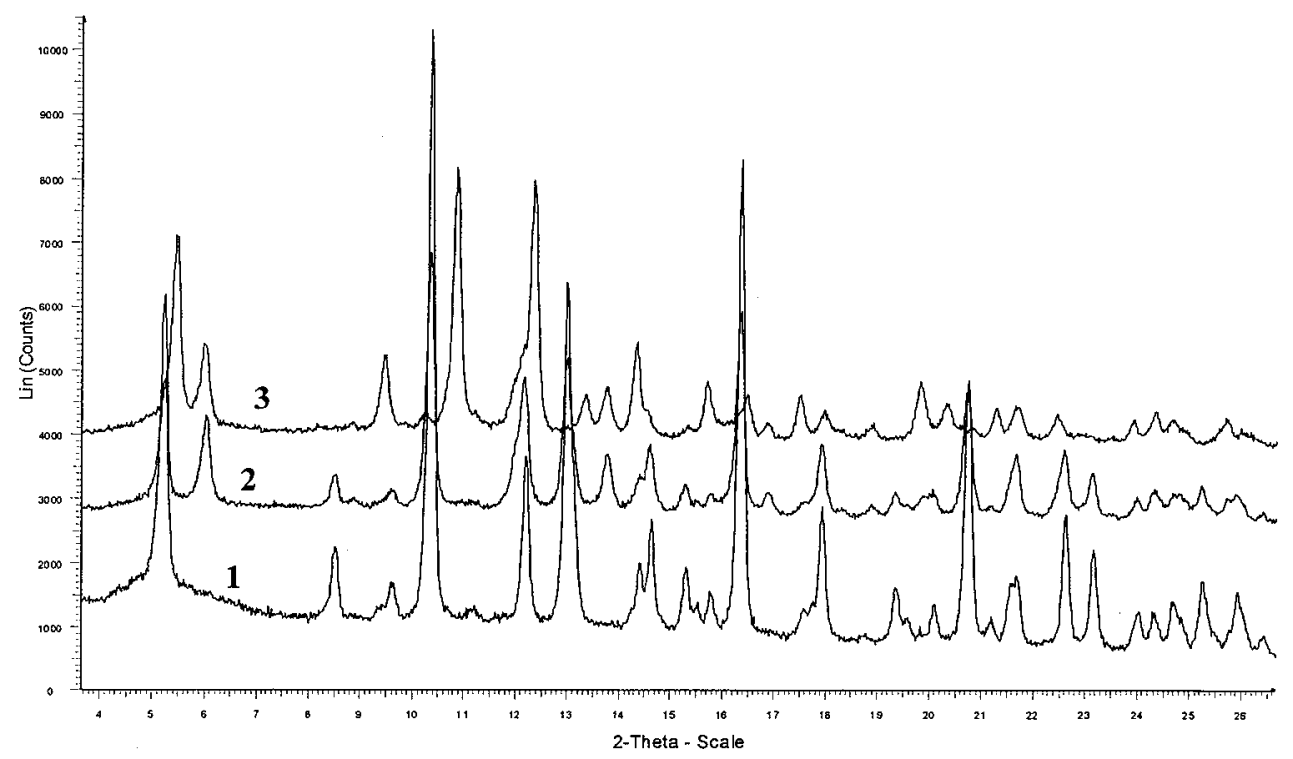

Figure 9. XRPD diagrams of 1 - docetaxel (trihydrate), 2 - hemihydrate and 3 - anhydrous form

The diagram recorded after cooling to room temperature, which differed from that of the anhydrous form and that of docetaxel, is similar to those of the substance recovered after water sorption-desorption analysis or maintained in a dry atmosphere at $298 \mathrm{~K}$.

The existence of a hemi-hydrate phase is consequently strengthened in keeping with DSC results. This form is relatively stable and the initial trihydrate phase could only be recovered by treatment for four weeks in a sealed dryer under $98 \%$ RH. To confirm these results, crystal structure determination of both phases (the hemi-hydrate and the anhydrous) is in progress.

\section{References}

[1] Mastropaolo D., Camerman A., Yuogang L, Brayer G.D. and Camerman N., Proc. Natl. Acad. Sci. USA, 92, (1995), 6920

[2] J. Giovannini, M.-A. Perrin, F. Leveiller et D. Louër, Direct space method and high resolution X-ray powder diffraction : a modern approach to pharmaceutical crystal structure determination, 19th European Crystallographic Meeting, Nancy 25-31 August 2000

[3] Gueritte-Voegelein F., Guenard D., Mangatal L. et Potier P., Guilhem J., Cesario M. and Pascard C., Acta Cryst., C46, (1990), 781

[4] Boultif A. and Louër D., J. Appl. Cryst., 24, (1991), 987

[5] Mighell A.D., Hubbard C.R. and Stalick J.K.,1981, NBS*AIDS80

[6] Engel G.E., Wilke S., König O., Harris K.D.M. and Leusen F.J.J., J. Appl. Cryst., 32, (1999), 1169 